\title{
A Construção da Paz no Cenário Internacional: Do Peacekeeping Tradicional às Críticas ao Peacebuilding Liberal ${ }^{1}$
}

\author{
Building Peace in the International Scene: \\ From the Traditional Peacekeeping to the Critic \\ of Liberal Peacebuilding
}

DOI: $10.21530 /$ ci.v13n2.2018.775

Lucas Guerra²
Ramon Blanco ${ }^{3}$

\section{Resumo}

O presente artigo tem por objetivo fazer uma contextualização geral a respeito das operações de paz das Nações Unidas. Primeiramente, enfatiza-se a possível relação entre o desenvolvimento histórico dessas operações e os distintos contextos internacionais no qual se inserem. Um maior destaque é dado às operações de paz contemporâneas, especialmente as de peacebuilding. São investigados os pressupostos normativos subjacentes ao modelo de atuação dessas, suas características centrais e as principais críticas que recebem em sua configuração atual. Com base em uma metodologia essencialmente qualitativa, com ampla revisão bibliográfica acerca do tema, foi possível constatar que o modo de atuação assumido pelas operações de paz é responsivo às tendências e agendas assumidas em um contexto internacional mais amplo. No caso das operações de peacebuilding, verifica-se que assimilam

1 Os autores agradecem aos revisores e pareceristas do artigo pelos comentários, sugestões e contribuições realizadas. Qualquer erro ou inconsistência, no entanto, são de nossa inteira responsabilidade.

2 Lucas Guerra é mestrando no Programa de Pós-Graduação em Relações Internacionais do Instituto de Relações Internacionais da Pontifícia Universidade Católica do Rio de Janeiro (IRI/PUC-Rio).

E-mail: lucaspxguerra@gmail.com. O presente trabalho foi realizado com apoio da Coordenação de Aperfeiçoamento de Pessoal de Nível Superior — Brasil (CAPES) — Código de Financiamento 001.

3 Ramon Blanco é Docente da Universidade Federal da Integração Latino-Americana (UNILA), onde coordena o Núcleo de Estudos para a Paz (NEP) e a Cátedra de Estudos para a Paz (CEPAZ), além de colaborar no Programa de Pós-Graduação em Ciência Política da Universidade Federal do Paraná (PPGCP-UFPR).

E-mail: ramon.blanco@unila.edu.br. O autor agradece o auxílio à pesquisa recebido no âmbito do Auxílio ao Pesquisador (Edital PRPPG No 109/2017) e do Apoio à Participação de Docentes em Eventos Científicos (Edital PRPPG No 58/2018) da Pró-Reitoria de Pesquisa e Pós-Graduação da UNILA.

Artigo submetido em 09/03/2018 e aprovado em 15/05/2018. 
em suas diretrizes os princípios da "paz liberal” dominantes no cenário internacional pós-Guerra Fria, buscando disseminar democracias liberais orientadas para o livre mercado como estratégia ideal para a construção da paz em cenários pós-conflito. Há, porém, uma série de críticas à forma de atuação das operações de paz nesses cenários, desde algumas de caráter procedimental até aquelas estruturais que questionam os próprios pressupostos normativos da paz liberal e sua incidência junto às populações locais.

Palavras-chave: Operações de Paz; Peacebuilding; Paz Liberal.

\begin{abstract}
This paper aims to weave a contextualization about the Unites Nations' peace operations. Firstly, we emphasize the possible relations between the historical development and the distinct international contexts in which they take place. We highlight the contemporary peace operations, specially the peacebuilding ones. We investigate the normative assumptions underlying their actuation, as well as their main characteristics ant the major critics they receive in their current configuration. With an essentially qualitative methodology, based in an extensive bibliographic review on the theme, we verified that the modus operandi assumed by the peace operations is responsive to the tendencies and agendas adopted in a wider international context. In the peacebuilding operations' case, we found that they assimilate the "liberal peace" principles, dominants in the international scenario post-Cold War. Therefore, they tend to disseminate liberal democracies oriented to free market as the ideal strategy to build peace in post-conflict scenarios. However, there are a number of criticisms on the actuation of the peace operations under these assumptions, from the procedural ones to those structural, which question the liberal peace's normative assumptions and their incidence on local populations.
\end{abstract}

Keywords: Peace Operations; Peacebuilding; Liberal Peace.

\title{
Introdução
}

As operações de paz da Organização das Nações Unidas (ONU) são, como afirmam Mônica Herz, Andrea Hoffmann e Jana Tabak (2015, p. 84), a principal ferramenta da organização para a gestão dos conflitos e promoção da segurança e da paz internacionais. De acordo com o Departamento das Nações Unidas para as Operações de Paz (DPKO), tais operações são frequentemente conduzidas com o apoio de múltiplos atores internacionais - tanto estatais quanto não estatais podendo ainda envolver um amplo gama de atividades: da diplomacia preventiva à 
construção de mecanismos institucionais de governança (peacebuilding) e mesmo o uso da força para impor o início de processos de pacificação (DPKO, 2008, p. 17-19).

Tendo em vista a importância fundamental das operações de paz da ONU enquanto ferramentas de política internacional para a segurança e a paz, o presente artigo tem por objetivo fazer uma exposição de algumas das características centrais das mesmas, de como essas características se modificam de acordo com contextos internacionais diversos. Nesse sentido, o objetivo do artigo é delinear um panorama de distintas abordagens teóricas feitas em relação às operações de paz, bem como de algumas das principais críticas direcionadas a tais operações. Assim, pretende-se contribuir com um marco de referência para possíveis estudos e investigações mais profundas sobre o tema. Para tanto, optou-se por uma metodologia essencialmente qualitativa, baseada na sistematização e análise tanto de fontes primárias - com ênfase para documentos publicados por agências do Sistema ONU abordando temas correlatos às operações de paz - quanto de fontes secundárias, com ampla revisão bibliográfica da produção acadêmica sobre o tema.

Nesse sentido, a primeira seção do artigo apresenta a distinção entre as operações de paz ditas "tradicionais" e as "multidimensionais", buscando relacionar cada um desses modelos com o contexto histórico no qual se desenvolveu. A seção traz ainda uma análise de alguns aspectos da "paz liberal” enquanto princípio normativo que orienta as operações de paz multidimensionais contemporâneas. A segunda seção, por sua vez, contém em suas respectivas subseções um panorama das principais críticas direcionadas às operações de paz contemporâneas, desde as que aqui chamamos "procedimentais" até as distintas vertentes de críticas "estruturais", com especial atenção àquelas orientadas pela Teoria Crítica das Relações Internacionais ${ }^{4}$ e por perspectivas pós-estruturalistas e pós-coloniais.

\section{As operações de paz da ONU: do modelo tradicional ao multidimensional}

Enquanto ferramentas centrais para a gestão de conflitos e crises internacionais, as operações de paz da Organização das Nações Unidas invariavelmente passaram

4 Seguindo o exemplo de Baete Jahn (1998, p. 614-615), por “Teoria Crítica das Relações Internacionais” — com as letras em maiúsculo - nos referimos às abordagens teóricas à disciplina de Relações Internacionais que partem de pressupostos normativos originalmente inspirados pela Escola de Frankfurt, buscando questionar a pretensão de neutralidade das abordagens positivistas e orientar teoricamente caminhos para a emancipação humana e superação de estruturas de dominação. Especificamente nesse trabalho, enfatizamos a vertente neogramsciana desse tipo de abordagem, inaugurada nos escritos de Robert Cox (1981). 
por uma série de transformações em suas configurações e modos de atuação ao longo da história da organização (PARIS, 2004, p. 13-17). Tais transformações ocorrem sobretudo em função dos elementos apontados como "ameaças" à paz e à segurança internacionais em determinados contextos históricos, bem como dos dispositivos então considerados adequados para a resolução das "ameaças" nesses mesmos contextos (BUZAN; HANSEN 2012, p. 37-38). Assim, para uma compreensão mais aprofundada acerca das operações de paz e do papel que desempenham na política internacional contemporânea, se faz necessária uma apresentação da relação indissociável dessas com movimentos mais amplos em evidência nas relações internacionais em momentos históricos específicos.

Nesse sentido, são paradigmáticas as transformações em curso na configuração das operações de paz no período de transição da bipolaridade sistêmica vigente durante a Guerra Fria para a ordem internacional pós-Guerra Fria (PARIS, 2004, p. 13). Seguindo os apontamentos de Barry Buzan e Lene Hansen (2012, p. 118-121) e de Paul Williams (2008, p. 3), destaca-se que, durante a Guerra Fria, prevaleceu na narrativa ortodoxa acerca da paz e da segurança internacionais um caráter estritamente militarista e estatocêntrico. Assim, de acordo com os autores, o paradigma de tensão bipolar vigente naquele período levou à priorização de temas relacionados à eclosão de conflitos interestatais e à corrida armamentista, com ênfase para os temas de dissuasão nuclear. No que diz respeito à paz, prevalecia uma noção baseada na manutenção do equilíbrio na balança de poder entre os Estados e no respeito à soberania de cada ator estatal (BELLAMY; WILLIAMS; GRIFFIN, 2010, p. 29). Resulta daí aquilo que Oliver Richmond (2010, p. 16-17) chama de "primeira geração" das abordagens à paz internacional, caracterizada pela gestão de conflitos entre Estados a partir da mediação promovida por uma terceira parte enviada para promover a paz.

Frequentemente, essa "terceira parte" consistia naquilo que Alex Bellamy, Paul Williams e Stuart Griffin (2010, p. 29) chamam de operações de "peacekeeping (manutenção da paz) tradicional” das Nações Unidas. Tratam-se, de acordo com Roland Paris (2004, p. 13), de operações caracterizadas por forças militares multinacionais compostas por uma quantidade restrita de soldados levemente armados, enviados para monitorar processos de cessar-fogo e patrulhar zonas neutras entre ex-combatentes. Em sua atuação, essas operações seguem o que Bellamy Williams e Griffin (2010, p. 173) denominam de "santíssima trindade" das operações de paz tradicionais: (1) o consentimento entre todas as partes beligerantes como condição sine qua non para o envio das forças de paz; 
(2) a não ingerência em assuntos domésticos, em respeito à soberania estatal, e (3) a proibição do uso da força exceto para fins de legítima defesa ${ }^{5}$.

Há ainda outros elementos que contribuem para o entendimento do porquê da prevalência do modelo "tradicional" de operações de paz durante a vigência da Guerra Fria. Roland Paris (2004, p. 15), por exemplo, destaca que naquele contexto de bipolaridade tanto os Estados Unidos quanto a União Soviética buscavam exercer controle direto sobre suas respectivas zonas de influência, evitando ao máximo a mediação de atores externos nessas regiões. Tal perspectiva de política externa presente em ambas as superpotências levou ao que Herz, Hoffmann e Tabak (2015, p. 88) identificam como uma "guerra de vetos" no Conselho de Segurança das Nações Unidas (CSNU) - forma de travar o processo decisório do organismo para medidas de caráter mais interventor. Além disso, a disputa ideológica entre os EUA e a URSS resultava na ausência de um modelo de governança política e econômica consensualmente aceito pela comunidade internacional como padrão a ser implementado nas sociedades pós-conflito (PARIS, 2004. p. 15). Soma-se a isso a ausência na própria Carta da ONU de prerrogativas específicas acerca das operações de paz, além da proibição explícita nessa a intervenções externas em assuntos domésticos ${ }^{6}$ (BLANCO, 2014, p. 269).

As transformações globais deflagradas pelo término da Guerra Fria tiveram um forte impacto sobre os paradigmas de paz e segurança internacionais e, consequentemente, sobre a configuração das operações de paz "tradicionais" vigentes até então. Nesse sentido, um dos desdobramentos centrais da dissolução da URSS e "vitória" dos Estados Unidos foi o encerramento dos massivos auxílios econômicos e militares ofertados pelas superpotências a suas respectivas zonas de influência durante a vigência do conflito bipolar (PARIS, 2004). O resultado da interrupção de tais fluxos de ajuda internacional foi a eclosão de intensas crises sociais, políticas e econômicas em diversos países da periferia global (PARIS, 2004, p. 16). Dessas crises emergiram uma série de grupos rebeldes de atuação violenta, geralmente tendo como objetivo central a tomada de controle sobre os escassos

5 As duas primeiras operações de paz enviadas pela ONU são exemplos paradigmáticos desse tipo de operação. Foram elas a Organização das Nações Unidas para a Supervisão de Trégua (UNTSO/1948) — criada para monitorar as primeiras tentativas de negociação de acordos de paz na Primeira Guerra Árabe-Israelense - e a Força de Emergência das Nações Unidas (UNEF I/1956), enviada para amenizar a Crise de Suez (BELLAMY; WILLIAMS, 2010, p. 176-177; THEOBALD, 2009, p. 1-4).

6 Por esse motivo, as primeiras operações de paz da ONU — de tipo "tradicional” — foram juridicamente baseadas no Capítulo VI da Carta das Nações Unidas, que versa sobre a resolução pacífica de disputas interestatais (HERZ; HOFFMANN; TABAK, 2015, p. 92). 
recursos de seus respectivos Estados (KALDOR, 2013, p. 2-3). A esse objetivo se somaram reivindicações e disputas de cunho étnico, religioso e identitário, processo que resultou na multiplicação de graves conflitos intraestatais ao redor do globo7 (KALDOR, 2013, p. 2-3).

Outro importante elemento do cenário pós-Guerra Fria foi a consolidação de um momento de unipolaridade sistêmica em torno da supremacia estadunidense, com a ausência momentânea de forças significativas de contestação global a essa ordem (BUZAN; HANSEN, 2012, 257-258). Um dos reflexos dessa situação foi uma considerável universalização do liberalismo político e econômico, à época defendido e representado principalmente pelos EUA (PARIS, 2004, p. 19). Assim, teses de autores como Francis Fukuyama (1989, p. 3), apontando a democracia liberal e o capitalismo de livre mercado enquanto estágios máximos e inevitáveis da evolução político-social humana, ganharam força nos meios profissionais e acadêmicos mundiais (PARIS, 2004, p. 19). Logo, as principais organizações internacionais, entidades políticas nacionais e demais entes de atuação global aderiram a essa retórica, passando a atuar no sentido de disseminar globalmente regras e modelos de governança radicados em princípios liberais (PARIS, 2004, p. 19).

A partir de então, formou-se um novo entendimento acerca daquilo em que consistiriam as principais “ameaças” à paz e à segurança e quais as estratégias ideais para combatê-las. No lugar de preocupações com ameaças bélicas e nucleares, emergiram enfoques em questões de identidade, fragilidade institucional, exclusão de minorias e subdesenvolvimento econômico, identificadas como possíveis raízes da eclosão de conflitos civis violentos (BLANCO, 2014, p. 270). Oliver Richmond (2010, p. 19) categoriza tal percepção como marco fundamental da "segunda geração" das abordagens à paz internacional, cuja principal característica é o reconhecimento da negação de necessidades humanas básicas - sejam elas políticas, econômicas, culturais, psicológicas etc. - enquanto força propulsora da emergência de conflitos intraestatais, notadamente na periferia global.

Assim, surgem categorias como a de "Estados falidos", referentes a entidades estatais apontadas como incapazes de garantir a segurança, o estado de direito e o bem-estar econômico e social de suas próprias populações (HELMAN;

7 Therése Pettersson e Peter Wallensteen (2015, p. 539) registram que os cinco primeiros anos posteriores à queda do muro de Berlim (1989-1994) foram marcados pela maior ocorrência desse tipo de conflito desde o fim da II Guerra Mundial até a contemporaneidade, com um ápice de cinquenta conflitos civis violentos registrados em 1991. 
RATNER, 1992, p. 3-6). Como pontua Blanco (2014, p. 294-295), tais Estados passam a ser apontados pela narrativa ortodoxa como uma dupla ameaça: à segurança de seus próprios cidadãos - por violar sistematicamente seus direitos fundamentais - e à segurança da região em que se inserem e à segurança internacional de maneira geral, uma vez que se vincula os "Estados falidos" à produção de instabilidades, conflitos, grupos terroristas, crises migratórias, dentre outras possíveis ameaças. Logo, o combate à "falência” dos Estados e aos conflitos intraestatais violentos gerados por tal falência passa a ser prioridade na agenda de construção de segurança e paz internacionais. Forma-se uma narrativa triangular na qual a segurança, o desenvolvimento e a paz são apontados como vértices indissociáveis e complementares que orientam as ações internacionais em cenários pós-conflito (BLANCO, 2014, p. 272).

Progressivamente, a "santíssima trindade" das operações de paz tradicionais vai se tornando obsoleta: diante da incapacidade de alguns Estados periféricos de exercerem aquelas que se consideram as suas "funções primordiais" intervenções externas - por vezes com uso da força - para "capacitá-los" passam a ser legitimadas perante a comunidade internacional (BELLAMY; WILLIAMS; GRIFFIN, 2010, p. 29-30). Nesse processo, as organizações internacionais principalmente o Sistema ONU e as instituições financeiras internacionais passam a exercer protagonismo nos processos de intervenção e "reconstrução" institucionais de cenários pós-conflito como estratégia para promover a segurança e a paz (HERZ; HOFFMANN; TABAK, 2015, p. 88).

Nesse sentido, o documento Uma Agenda para a Paz, redigido em 1992 pelo à época Secretário-Geral das Nações Unidas Boutros Boutros-Ghali, é paradigmático por marcar o autorreconhecimento da ONU enquanto principal entidade responsável pela garantia e manutenção da paz e da segurança internacionais (UN 1992, p. 1-3). Além disso, o documento traz um inédito delineamento mais preciso do entendimento da organização acerca do conceito de "paz" e quais são os instrumentos mais adequados para concretizá-la (BLANCO, 2014, p. 275).

Na perspectiva do documento, a "paz" é entendida como a existência, em uma sociedade, de condições de participação política democrática, garantia de acesso popular ao desenvolvimento social e econômico e de mecanismos institucionais de governança que assegurem o pleno funcionamento do estado de direito (UN, 1992, p. 12-13). Quanto às políticas consideradas mais adequadas para se alcançar essa

8 De acordo com a narrativa internacional convencional: garantir a lei e a ordem, o pleno controle e autoridade soberana sobre o território e a segurança e o bem-estar de sua população (HELMAN; RATNER, 1992, p. 3). 
condição, a Agenda para a Paz (1992, p. 7-12) apresenta cinco possíveis ferramentas para a resolução de conflitos e promoção da paz ao redor do globo. A primeira delas, denominada diplomacia preventiva, refere-se a um conjunto de táticas de prevenção à eclosão de conflitos violentos, envolvendo principalmente a mediação por parte da ONU, a pedido dos Estados em litígio e de acordo com as regras definidas por eles (UN, 1992, p. 4). As outras quatro dizem respeito aos distintos tipos de operações de paz, a saber: operações de peacemaking ("pacificação"), peace-enforcement ("imposição da paz"), peacekeeping ("manutenção da paz") e peacebuilding ("construção da paz")

As operações de peacemaking ("pacificação") são aquelas cujo objetivo é trazer as partes beligerantes para um acordo, utilizando para tanto os meios estritamente pacíficos previstos no Capítulo VI da Carta de São Francisco (UN, 1992, p. 7). Em sentido diametralmente oposto, as operações de peace-enforcement ("imposição da paz”) apresentam uma clara ruptura com os princípios das operações de paz tradicionais, apelando diretamente para o respaldo do Capítulo VII da Carta da ONU para justificar o uso da força na imposição da vontade do Conselho de Segurança das Nações Unidas (CSNU) sobre partes beligerantes violentas relutantes em aceitar um processo de negociação política por vias pacíficas e que consistam em ameaça a suas respectivas populações civis (UN, 1992, p. 9-10).

Quanto às operações de peacekeeping ("manutenção da paz”), por um lado, elas podem seguir o já referenciado modelo tradicional que vigorou ao longo da Guerra Fria, mantendo-se fieis aos princípios da santíssima trindade (consentimento, imparcialidade e proibição do uso da força) (UN, 1992, p. 10-11). Por outro lado, a Agenda para a Paz prevê a possibilidade de uma atuação mais versátil por parte dessas operações, podendo ser enviadas para cenários de violência ainda em curso e tendo prerrogativa, portanto, para o uso da força para garantir a manutenção da paz ${ }^{9}$ (UN, 1992, p. 11). Seus mandatos podem ser mutáveis ao longo da operação, seu pessoal composto por múltiplos atores estatais e não estatais e suas atividades abrangem desde o patrulhamento de zonas neutras à separação coercitiva de forças beligerantes e à proteção de civis e funcionários internacionais em cenários de conflito (UN, 1992, p. 11-12).

Finalmente, as operações de peacebuilding ("construção da paz") são aquelas orientadas para a resolução das causas estruturais dos conflitos, tendo

9 Nesse sentido, Bellamy, Williams e Griffin (2010, p. 194) apontam que é corrente a categorização dessas operações como juridicamente regidas pelo "capítulo 6 1⁄2” " da Carta de São Francisco, entre os princípios pacíficos e consensuais do Capítulo VI e as medidas de coerção previstas em seu Capítulo VII. 
por objetivo central evitar a reincidência dos mesmos (UN, 1992, p. 12). Assim, uma vez que as injustiças sociais, disparidades econômicas e opressões políticas são fatores compreendidos como raízes profundas da eclosão e reincidência de conflitos violentos, a resposta oferecida pelas Nações Unidas é a promoção de instituições e sistemas de governança capazes de combater tais raízes, favorecendo o estabelecimento de uma paz autossustentável e de longa duração (RICHMOND, 2004, p. 37). Esse processo é implementado pelas operações de peacebuilding que, para tanto, devem contar com a coordenação de diversos atores da comunidade internacional, dentre os quais as organizações internacionais (com ênfase ao sistema ONU), blocos regionais, instituições financeiras internacionais, ONGs, agências de desenvolvimento, dentre outros responsáveis pela (re)construção da paz em cenários pós-conflito (PARIS, 2002, 639-641; UN, 1992, p. 13-14).

Analisando as ferramentas previstas pela ONU na Agenda para a Paz à luz das já referidas mudanças em curso na concepção de paz e segurança internacionais no contexto pós-Guerra Fria, é possível notar uma maior abertura a medidas de caráter interventor no direcionamento das ações da organização. Nesse sentido, Bellamy, Williams e Griffin (2010, p. 279-281) notam que, mediante a "narrativa triangular" vinculando segurança, desenvolvimento e paz, as operações de peacebuilding se apresentam como a ferramenta mais adequada para a administração contemporânea da paz e da segurança internacionais. Isso porque a um só tempo mesclam o potencial de uso da força com a possibilidade de realização de atividades voltadas para a reconstrução e remodelamento das instituições de governança social, política e econômica dos países em situação pós-conflito (KOTZÉ, 2010, p. 219).

Tendo em vista essa importância, em 2008 o Departamento de Operações de Paz das Nações Unidas (DPKO) publicou a Doutrina Capstone, documento que reforça a centralidade das operações de peacebuilding como ferramentas centrais para a gestão da paz e conflitos no cenário internacional contemporâneo. No documento, são delineadas quatro diretrizes estratégicas para esse tipo de operação, sendo elas: (1) a restauração da capacidade do Estado prover ordem e segurança à sua população; (2) o fortalecimento do estado de direito e dos direitos humanos; (3) o apoio à estruturação de instituições políticas legítimas, respaldadas pela participação popular; (4) a promoção do desenvolvimento econômico e social (DPKO, 2008, p. 23).

Para tanto, tais operações se ocupam de atividades diversas, que em muito ultrapassam aquelas das operações de paz tradicionais. Dentre elas, destacam-se o desarmamento, desmobilização e reintegração de combatentes (DDR), processos de 
repatriação, treinamento de pessoal policial e militar, organização e monitoramento de eleições, redação de constituições, reconstrução de infraestrutura básica, provisão de alimentos e medicamentos, reconstrução e treinamento institucional/ administrativo dos sistemas judiciário, legislativo e executivo dos países pós-conflito, dentre outras (BLANCO, 2014, p. 299; PARIS, 2004, p. 18). Para desenvolver esse amplo leque de funções, as operações de peacebuilding geralmente contam com grandes efetivos militares para eventuais necessidades coercitivas, mas que são lideradas por funcionários públicos internacionais de organizações civis, responsáveis pela reconstrução institucional priorizada nesse tipo de operação (BELLAMY; WILLIAMS; GRIFFIN, 2010, p. 279-283). Pela amplitude de tarefas desempenhadas pelas operações de peacebuilding, autores como Giovanni Cellamari (1999, p. 60) e Oliver Richmond (2010, p. 22) as categorizam como operações de paz multidimensionais.

Uma importante característica que as operações de peacebuilding assumem em sua configuração contemporânea e que vale a pena ser apresentada mais detalhadamente é a intrínseca relação com processos de state-building (BELLAMY; WILLIAMS; GRIFFIN, 2010, p. 257). Os processos de state-building são uma parte específica das múltiplas atividades conduzidas pelas operações de peacebuilding, especificamente voltados para a restauração e treinamento do serviço civil e administrativo, fortalecimento da gestão financeira, capacitação dos poderes executivo, legislativo e judiciário para exercer governo e a gestão das relações entre Estado e sociedade civil (BLANCO, 2014, p. 298-299). Em suma, trata-se de uma reconstrução das bases institucionais e infraestruturais do Estado para que esse possa estabelecer efetivamente a governança sobre um território a partir daquelas que são consideradas suas funções primordiais: o fornecimento de segurança física, social e econômica à população e a regulação das relações dessa com o aparato estatal, de modo a prevenir a emergência de novos conflitos violentos (BELLAMY; WILLIAMS; GRIFFIN, 2010, p. 257 ; BLANCO, 2014, p. 301-303) ${ }^{10}$.

Oliver Richmond (2010, p. 22) caracteriza essa convergência entre as operações de peacebuilding e os processos de state-building como a característica fundamental do que chama de "terceira geração" das abordagens internacionais à construção da paz. A partir dessa convergência, emerge o que o autor caracteriza como um "consenso sobre peacebuilding" - o entendimento, compartilhado entre as

10 Para uma análise crítica mais alargada relativamente a um caso onde tal relação é a emblemática, no TimorLeste, ver (BLANCO, 2015). 
principais organizações envolvidas com as operações de paz, de que a reconstrução das capacidades de governança estatal via processos de state-building seria a estratégia ideal para promover uma paz autossustentável e de longa duração em cenários pós-conflito (RICHMOND, 2010, p. 22).

É importante notar que o "consenso sobre peacebuilding" foi arquitetado em um ambiente marcado por uma aceitação generalizada da democracia liberal e do capitalismo de livre mercado enquanto princípios triunfantes da governança internacional (PARIS, 2004, p. 19). Tendo em vista tal contexto, autores como Mark Duffield (2001, p. 10-11), Michael Pugh (2004, p. 40), Oliver Richmond (2004, p. 91-91), Ramon Blanco (2014, p. 284-285) e Roland Paris (2002, p. 642) convergem ao indicar que o "consenso sobre peacebuilding" que orienta as operações de paz contemporâneas consiste na institucionalização de um modelo específico e pretensamente universal de reconstrução de Estados e sociedades pós-conflito, voltado para a promoção de democracias liberais orientadas para o livre mercado enquanto estratégia ideal para a consolidação de sistemas de governança estáveis e funcionais e para a concretização de uma paz de longa duração. São essas as diretrizes da chamada paz liberal.

Como lembram Oliver Richmond (2005, p. 25-28), Ramon Blanco (2014, p. 280-282) e Roland Paris (2004, p. 47-50), o enquadramento normativo que rege a paz liberal aplicada pelas operações de peacebuilding contemporâneas tem suas raízes no pensamento liberal ocidental emergente com os filósofos da Ilustração. Assim, argumentos inicialmente levantados por autores como Adam Smith (1988), Immanuel Kant (2008), John Locke (1978), Montesquieu (1996) e mesmo federalistas estadunidenses, como James Madison, Alexander Hamilton e John Jay (1993), são reeditados como pressupostos norteadores do modelo de governança política, social e econômica proposto pelas operações de paz.

Dentre esses pressupostos, destacam-se os relacionados à argumentação em torno das teses da "paz democrática" e da "paz pelo comércio". Em suma, como sintetiza Blanco (2014, p. 280), trata-se da pressuposição de que (1) regimes democráticos são menos propensos a conflitos violentos internos e externos e (2) o livre comércio e a interdependência econômica gerada por ele consistem em um plataforma sólida para a manutenção da paz. Nas operações de peacebuilding contemporâneas e processos de state-building conduzidos por elas, tais perspectivas se cristalizam na: 
noção de que promover a "liberalização" em países que recentemente experimentaram guerra civil ajudaria a criar as condições para uma paz estável e duradoura. Na esfera política, liberalização significa democratização, ou a promoção de eleições periódicas e genuínas, limitações constitucionais ao exercício do poder governamental e respeito pelas liberdades civis básicas [...] Na esfera econômica, liberalização significa mercantilização, ou movimento em direção a um modelo econômico orientado para o mercado, incluindo medidas orientadas a minimizar a intervenção governamental na economia e maximizar a liberdade de investidores, produtores e consumidores privados para buscar seus respectivos interesses econômicos ${ }^{11}$ (PARIS 2004, p. 5, tradução nossa).

Com base na prevalência desses argumentos na narrativa internacional pósGuerra Fria, a democracia liberal orientada para o livre mercado passa a ser o modelo de organização política, social e econômica considerado ideal para a promoção da paz, da segurança e do desenvolvimento em países devastados por conflitos (DUFFIELD, 2001, p. 10-11). Logo, as diretrizes promovidas pelas operações que Richmond (2004, p. 91-92) caracteriza como de "peacebuilding liberal” assumiram o perfil de promoção de sistemas de governança mais que de meros processos de reconciliação. Subjacente ao “consenso sobre peacebuilding”, portanto, estava a noção de que a concretização de uma paz autossustentável e duradoura em sociedades pós-conflito só seria possível mediante a adoção dos princípios da democratização, do estado de direito funcional, dos direitos humanos individuais, da inserção ao livre mercado mundial e do modelo de desenvolvimento neoliberal (BLANCO, 2014, p. 280).

Na esfera econômica, Michael Pugh (2005, 23-25) identifica que as operações de peacebuilding tendem à implementação de modelos de governança econômica norteados por uma concepção de desenvolvimento notadamente neoliberal. Assim, são propostas diretrizes centradas na liberalização dos mercados, na redução da gestão estatal sobre a economia, na supressão dos espaços públicos e coletivos em detrimentos das privatizações e investimentos (principalmente externos) privados e na crença de que tais diretrizes, em conjunto com as exportações, são

11 "the notion that promoting "liberalization" in countries that had recently experienced civil war would help to create the conditions for a stable and lasting peace. In the political realm, liberalization means democratization, or the promotion of periodic and genuine elections, constitutional limitations on the exercise of governmental power, and respect for basic civil liberties [...]. In the economic realm, liberalization means marketization, or movement toward a market-oriented economic model, including measures aimed at minimizing government intrusion in the economy, and maximizing the freedom for private investors, producers, and consumers to pursue their respective economic interests". 
elementos fundamentais para o crescimento econômico e promoção do bem-estar social (PUGH, 2005, p. 25). No eixo político, Paris (2004, p. 5) nota a tentativa de implementação de um modelo de democracia estritamente baseado na promoção de eleições periódicas de representantes e na instituição de limitações constitucionais ao poder dos Estados em situação pós-conflito.

Evidentemente, esse tipo de orientação das operações de peacebuilding sob a égide da paz liberal foi progressivamente gerando uma série de críticas entre diversos atores da comunidade internacional, desde setores da academia até algumas das próprias organizações internacionais envolvidas com a resolução de conflitos. Dentro do objetivo do artigo de apresentar uma ampla contextualização acerca das operações de paz, a exposição de algumas dessas críticas é o objetivo ao qual se presta a seção seguinte.

\section{Perspectivas críticas às operações de peacebuilding contemporâneas}

Conforme se mencionou, apesar do termo "consenso sobre peacebuilding", se verifica que uma série de críticas e contrapontos surgem a tal paradigma estruturado em torno dos princípios da paz liberal, especialmente nos meios acadêmicos, mas também entre algumas agências civis de construção da paz (BELLAMY; WILLIAMS; GRIFFIN, 2010, p. 259-265). Seguindo o exemplo de Aureo de Toledo Gomes (2013, p. 50), propomos aqui uma divisão em dois tipos principais de crítica: as procedimentais (ou, nos termos de Gomes, "reformistas") e as estruturais.

As críticas que aqui chamamos "procedimentais" são aquelas que não questionam os pressupostos teóricos e ideológicos da paz liberal, apenas divergem acerca das melhores estratégias para avançar em relação à democratização e mercantilização das sociedades pós-conflito, além de denunciar alguns desafios pragmáticos que se manifestam nas operações de paz, como a disseminação de doenças e abusos sexuais. Já as críticas "estruturais” envolvem um questionamento dos pressupostos normativos das operações de peacebuilding liberal, buscando evidenciar as conexões existentes entre essas e as relações de poder existentes no cenário internacional. Dentre as críticas estruturais, apresentam-se nessa seção aquelas realizadas a partir da Teoria Crítica e de enfoques pós-estruturalistas e pós-coloniais. 


\section{As críticas procedimentais}

Entre as críticas de tipo procedimental às operações de peacebuilding contemporâneas, Ramon Blanco (2014, p. 283-284) ressalta aquelas mais diretamente relacionadas a falhas na organização, centralização e planejamento na atuação das diversas agências internacionais envolvidas com as operações de paz. Nesse sentido, se enquadram as críticas feitas por Bellamy, Williams e Griffin (2010, p. 248) aos mandatos do Conselho de Segurança da ONU que orientam tais operações, apontados como frequentemente imprecisos e inexequíveis. Os autores também ressaltam a recorrente carência de recursos humanos, financeiros e materiais suficientes para o cumprimento da ampla gama de atividades outorgado às operações de paz (BELLAMY; WILLIAMS; GRIFFIN, 2010, p. 248).

Outro enfoque crítico às operações de peacebuilding que pode ser alocado na categoria procedimental diz respeito aos efeitos econômicos negativos que essas podem acarretar nos locais em que atuam. Cedric de Coning, Chiyuki Aoi e Ramesh Takur (2007, p. 170-171), por exemplo, verificam que os grandes contingentes civis, policiais e militares que compõem as operações de paz tendem a gerar uma série de atividades econômicas em torno de suas demandas (moradia, hospedagem, alimentação, recursos humanos relacionados às próprias operações, serviços pessoais etc.). Apesar dessa demanda contribuir para a geração de empregos, os autores notam que também repercute em fatores danosos para as economias locais, como no aumento nos preços de insumos básicos e intensificação das desigualdades salariais, em benefício das parcelas que se aproximam de atividades de peacebuilding financiadas por agentes externos (CONING; AOI; TAKUR, 2007, p. 170-171). Além disso, a abrupta retirada do pessoal internacional após o término das operações frequentemente gera impactos econômicos negativos, principalmente vinculados ao desemprego e à deflação (CONING; AOI; TAKUR, 2007, p. 170-171) ${ }^{12}$.

Ainda entre as críticas de tipo procedimental, destacam-se aquelas que denunciam os casos de uso arbitrário da violência, abusos sexuais e estupros perpetrados pelo pessoal internacional das operações de paz contra as populações em cenários pós-conflito. Nesse sentido, Vanessa Kent (2007, p. 45), por exemplo, indica que nas operações de paz ocorridas na Somália, Haiti, Moçambique,

12 As operações de peacebuilding no Kosovo (UNMIK) e no Afeganistão (UNAMA) são, como reporta Katarina Ammitzboell (2007, p. 76-86), casos exemplares dos impactos econômicos negativos que podem ser provocados por esse tipo de operação. 
Kosovo, Bósnia e Camboja ao longo da década de 1990, os índices de prostituição, estupros, escravidão sexual e mesmo de abuso sexual de crianças cresceram exponencialmente, sem a devida punição dos agentes internacionais envolvidos em tais atividades.

Acrescenta-se, ainda, o apontamento de casos de transmissão de graves doenças infecciosas pelos contingentes das operações de paz. Harley Feldbaum, Kelley Lee e Preeti Patel (2006, p. 775-776) evidenciam ocorrências de transmissão de HIV/AIDS pelos efetivos de paz no Sudão do Sul e na Somália. José Luis Patrola e Thalles Gomes (2011, p. 149), por sua vez, indicam a disseminação de cólera pelas tropas da Missão das Nações Unidas para a Estabilização do Haiti (MINUSTAH), tendo atingido aproximadamente cem mil habitantes do país e que se verificou fatal para cerca de dois mil deles.

Finalmente, adiciona-se às críticas procedimentais aquelas que, apesar de concordarem com o argumento central da paz liberal de que a mercantilização e a democratização são as diretrizes de governança ideais para a construção de uma paz duradoura e autossustentável em cenários pós-conflito, propõem modos alternativos de implementá-las nesses cenários. Um exemplo é a proposição da “institucionalização antes da liberalização” feita por Roland Paris (2004, p. 187-211). Para o autor, a rápida liberalização política e econômica em cenário pós-conflito pode gerar efeitos traumáticos, inclusive contribuindo para a reincidência de episódios violentos. Sendo assim, a liberalização deveria se dar de modo gradual, precedida da construção e fortalecimento de instituições ${ }^{13}$ e culturas democráticas, capazes de mitigar possíveis tensões resultantes do processo de adequação aos moldes de governança liberal (PARIS, 2004, p. 187-211).

\section{As críticas estruturais: Teoria Crítica}

Enquanto as críticas procedimentais apresentadas na subseção anterior são estritamente voltadas para desafios e problemáticas pontuais enfrentadas pelas operações de paz, sem questionar seus pressupostos normativos, as abordagens de crítica estrutural às operações de peacebuilding liberal são aquelas que buscam compreender como essas operações e suas diretrizes contribuem para a

13 Partidos políticos moderados, mecanismos constitucionais de respeito aos resultados eleitorais, sistemas midiáticos livres que previnam o discurso de ódio, reformas econômicas progressivas etc. (PARIS, 2004, p. 188-205). 
legitimação e perpetuação das relações de poder inerentes a uma determinada ordem mundial (GOMES, 2013, p. 55). Aqui, destacam-se as críticas estruturais a partir da Teoria Crítica das Relações Internacionais, majoritariamente voltadas para a desmistificação da suposta neutralidade e universalidade apresentadas pelos princípios da paz liberal.

Nesse sentido, o objetivo dessas abordagens é analisar o papel ideológico da paz liberal - e das operações de paz orientadas por ela - na perpetuação de uma ordem mundial neoliberal. Também faz parte do enfoque da Teoria Crítica uma especial atenção ao papel das organizações internacionais nesse processo (BELLAMY; WILLIAMS; GRIFFIN, 2010, p. 28; RICHMOND, 2008, p. 121-122). Sendo assim, são três as dimensões das críticas estruturais, desde a perspectiva da Teoria Crítica, examinadas nessa subseção: (1) as operações de peacebuilding e a paz liberal como mecanismos de solução de problemas; (2) o papel desempenhado por elas na perpetuação de uma ordem mundial neoliberal e (3) a participação das organizações internacionais nesse processo.

Bellamy, Williams e Griffin (2010, p. 28) dão um primeiro passo no sentido da primeira dimensão, ao identificar qual seria o "problema" central a ser "solucionado" pelas operações de peacebuilding liberal na ordem mundial contemporânea. Trata-se, na perspectiva dos autores, da contenção de movimentos e processos que possam ameaçar a acumulação de lucro em escala mundial (BELLAMY; WILLIAMS; GRIFFIN, 2010, p. 28). Mais precisamente, esse viés analítico sustenta que o funcionamento da economia global capitalista tende a criar regiões periféricas no sistema internacional, cujas péssimas condições socioeconômicas frequentemente geram conflitos violentos (BELLAMY; WILLIAMS; GRIFFIN, 2010, p. 28). Ao mesmo tempo, as regiões centrais do sistema dependem dos fluxos de bens e capitais e da mão de obra e matéria-prima baratas disponibilizadas pelas regiões periféricas.

Assim, a paz liberal e as políticas públicas internacionais influenciadas por ela buscam essencialmente conter revoltas e conflitos que ameacem a ordem mundial capitalista estabelecida e, ao mesmo tempo, perpetuar e legitimar essa ordem (PUGH, 2004, p. 41). Assim, de acordo com Ian Taylor (2010, p. 169-170), as operações de peacebuilding orientadas pela paz liberal buscam sobretudo solucionar conflitos pontuais emergentes na periferia global, atendendo aos interesses de forças sociais transnacionais que se beneficiam da manutenção de certo grau de estabilidade nos países periféricos, em ordem de lograr explorar seus recursos e incluí-los à rede de fluxos de bens e capitais. 
A partir dessa constatação, é possível avançar um pouco mais a análise na direção do segundo ponto proposto no início da subseção: o papel das operações de peacebuilding liberal na perpetuação e legitimação de uma ordem mundial neoliberal. Robert Cox (1999, p. 8-12), um dos principais expoentes da Teoria Crítica das Relações Internacionais, aponta que uma das características centrais dessa ordem, no campo econômico, é uma organização da produção transnacionalizada e fragmentada - fortemente dependente dos recursos naturais e humanos baratos ofertados pelos países periféricos para funcionar. Ainda de acordo com o autor, no campo político prevalece uma forma de Estado enquanto aparato de adequação das economias nacionais às demandas liberalizantes do capitalismo global (COX, 1999, p. 8-12).

Conforme constatam autores como Edward Newman (2009, p. 49), Michael Pugh (2005, p. 24-35), Ian Taylor (2010, p. 160-162), Mark Duffield (2001, p. 34) e Paul Cammack (2006, p. 3-6), as operações de peacebuilding exercem um papel fundamental na disseminação do modelo de governança política e econômica favorável à perpetuação de uma ordem mundial neoliberal. Pugh (2005, p. 24-35), por exemplo, enfatiza que as diretrizes econômicas contidas nas proposições orientadas pela paz liberal se baseiam na integração indiscriminada à economia mundial como único caminho para o desenvolvimento e no protagonismo do setor privado e dos investimentos externos diretos nesse processo. Abre-se assim caminho para uma supressão dos bens e serviços públicos em prol das privatizações e investimentos estatais focados no setor privado (PUGH, 2005, p. 32-35). O resultado é a implementação de um modelo econômico que, na prática, intensifica a marginalização dos setores mais pobres da população, favorece as elites locais envolvidas com o capital transnacional e acentua as desigualdades socioeconômicas internas em sociedades pós-conflito (PUGH, 2005, 32-35).

Além disso, as operações de peacebuilding liberal disseminam um modelo de democracia estritamente procedimental, radicado em uma noção de nítida separação entre a esfera econômica e a esfera política do todo social (TAYLOR, 2010, p. 160-162). Assim, o modelo de democracia perpetuado pelas operações de peacebuilding tende a retirar o controle populacional democrático sobre processos econômicos e favorecer a manutenção no poder de elites políticas aliadas ao capital transnacional e à adequação local aos imperativos da ordem mundial neoliberal (ROBINSON, 2013, p. 228; TAYLOR, 2010, p. 162).

Em síntese, pela ótica da Teoria Crítica das Relações Internacionais, as operações de peacebuilding são lidas como ferramentas fundamentais das organizações 
internacionais em sua função de perpetuar e legitimar uma ordem mundial favorável aos interesses das forças sociais hegemônicas (elites transnacionais) em determinados momentos históricos (COX, 2007, p. 119; PUGH, 2004, p. 45; TAYLOR, 2010, p. 156). Desde esse enfoque, instituições como a ONU e suas agências, o Fundo Monetário Internacional (FMI), o Banco Mundial, a Organização para a Cooperação e o Desenvolvimento Econômico (OCDE), a União Europeia, a Organização dos Estados Americanos (OEA) e mesmo diversas ONGs e think tanks são apontadas como atores estruturantes da ordem mundial neoliberal contemporânea (CAMMACK, 2006, p. 1-6; COX, 2007, p. 119-121; PARIS, 2002, p. 641). Coordenando esse processo, haveria uma elite financeira e empresarial transnacional que coordena os processos de peacebuilding, buscando avançar a disseminação do neoliberalismo em escala global por intermédio das organizações internacionais, com ênfase para o Sistema ONU e para as instituições financeiras internacionais (PUGH, 2004, p. 46).

Como bem pontua Cammack (2006, p. 1), a atuação dessas organizações em questões securitária no pós-Guerra Fria se voltou principalmente para a construção de um paradigma de "segurança pela hegemonia capitalista", cuja consolidação se dá em grande parte pela atuação das operações de peacebuilding liberal. Para o autor, tais operações exercem um papel fundamental para a disseminação dos valores e imperativos capitalistas para os países periféricos, através da criação de mercados abertos para a penetração pelo capital transnacional, a capacitação de novos contingentes de trabalhadores baratos disponíveis para a exploração pelo capital externo, o estabelecimento de hegemonias domésticas burguesas e a asseguração da legitimidade desses processos via democracia liberal (CAMMACK, 2006, p. 6).

Com base nos argumentos apresentados, Michael Pugh (2004, p. 54) sustenta que haveria um preço a pagar pela ajuda humanitária e proteção militar por forças externas, representada pelas operações de peacebuilding liberal em cenários pós-conflito: a manutenção da dependência em relação às partes mais ricas do planeta e a sujeição às normas e demandas de uma economia neoliberal globalizada. Assim, embora o modelo de governança política e econômica proposto pela paz liberal possa trazer certos avanços para a participação democrática de massas populares e para o enriquecimento de elites nacionais, destaca-se que a transição em cenários pós-conflito sob o marco desse paradigma impõe uma série de limitações a posteriores avanços socioeconômicos para as classes populares (TAYLOR, 2010, p. 170). Nesse sentido, Taylor (2010, p.170) sustenta 
que as operações de peacebuilding liberal tendem a deixar como legado uma "paz virtual”, favorável aos interesses das elites transnacionais que as financiam, mas totalmente desvinculada - e, por vezes, prejudicial - às sociedades locais dos países nos quais se inserem.

\section{Outras perspectivas críticas estruturais}

A subseção anterior apresentou perspectivas críticas de cunho estrutural voltadas para a identificação da relação entre as operações de peacebuilding liberal e o contexto global mais amplo no qual essas se inserem. A presente subseção, por sua vez, apresenta outras perspectivas críticas que igualmente questionam os pressupostos normativos das operações de paz, porém com um enfoque mais direcionado aos seus impactos nas sociedades e populações locais. Nesse sentido, seguindo a categorização proposta por Aureo de Toledo Gomes (2013, p. 55), enfatizam-se as críticas influenciadas por perspectivas pós-estruturalistas e póscoloniais.

Desde um enfoque mais propriamente pós-estruturalista, mesclando conceitos foucaltianos com contribuições teóricas da Escola Inglesa das Relações Internacionais, Ramon Blanco (2017a, p. 85) sustenta que as operações de paz são dispositivos de "normalização" e "disciplinarização" de Estados e sociedades pós-conflito, consistindo portanto em ferramentas de exercício de governo (compreendido como "conduta das condutas") na sociedade internacional. Nesse processo, os modelos de Estado e de sociedade considerados "normais", devendo ser universalmente aplicados, são os dos Estados liberais-democráticos ocidentais - as democracias de livre mercado - , reproduzidos pelas operações de peacebuilding através de mecanismos de "disciplina” (punição e recompensa) e "biopolítica" (controle sobre meios de reprodução da vida da população) em cenários pós-conflito (BLANCO, 2017a, p. 85).

A partir de percepções semelhantes, emergem as críticas estruturais de caráter mais notadamente pós-colonial, baseadas principalmente na denúncia de ecos do colonialismo presentes nas operações de paz (GUERRA; BLANCO, 2017; PARIS, 2002, p. 637-641) e na busca por um protagonismo de atores locais nos processos de construção da paz em sociedades pós-conflito (RICHMOND, 2010, p. 26). No eixo das críticas que apontam possíveis traços colonialistas nas operações de paz, Jonathan Hill (2005, p. 148) foca nos processos de state-building implementados 
pelas operações de peacebuilding, indicando como tais processos partem de uma concepção pejorativa dos Estados periféricos, apontando-os como versões “depravadas" da versão de estatalidade pretensamente "correta" e "superior" verificada nos processos de formação estatal da Europa Ocidental.

Jarat Chopra (2002, p. 994-999) acrescenta a essa perspectiva uma crítica à objetificação das sociedades pós-conflito presente nas abordagens correntes à construção da paz, na qual as sociedades locais são abordadas como recipientes de fórmulas lideradas por atores externos, e não como agentes ativos dos processos de pacificação. Como consequência, David Chandler (2006, p. 189-195) nota que os processos de peacebuilding e state-building contemporâneos tendem a construir "Estados fantasmas", dotados de personalidade jurídica internacional, mas carentes de legitimidade política e social junto à sociedade local. A verificação dessa problemática das operações de paz contemporâneas deu origem àquela que Oliver Richmond (2010, p. 26) chama de "quarta geração" das abordagens à resolução de conflitos e construção da paz internacional, sendo essa fundamentalmente caracterizada pela "virada local", ou seja, a reivindicação do protagonismo local nos processos decisórios e ações práticas de construção da paz.

Nesse sentido, autores como David Roberts (2011, p. 20-22), Karolina Werner (2010, p. 72-73) e Robert Mac Ginty (2010, p. 348-352), por exemplo, defendem que uma paz autossustentável e de longa duração não poderia ser obtida pela imposição de modelos específicos de governança política, social e econômica protagonizada por atores externos, mas tão somente a partir de uma base em costumes locais, histórica e culturalmente enraizados na forma de viver da população nativa, e com o protagonismo ativo dessa nos processos de construção da paz. Mac Ginty (2010, p. 348-352), um dos principais expoentes dessa perspectiva, reivindica a inclusão da dimensão "indígena" nas operações de paz, de modo que essas passem a englobar técnicas de reconciliação e resolução de conflito próprias das tradições locais, voltando-se para as relações do dia a dia, práticas culturais e simbólicas e para o diálogo constante, mais do que para a mera celebração de acordos e tentativa de construção de instituições junto às elites locais.

O que o autor propõe, porém, não é a substituição completa da paz liberal por uma "paz indígena", mas sim um processo de hibridização entre ambas, de modo a gerar novos modelos de abordagem à construção da paz (MAC GINTY, 2010, p. 360-362). Richmond (2013, p. 79-86) também se coloca favorável à perspectiva de hibridização da paz, indicando que esse processo teria o potencial de utilizarse das ferramentas e possibilidades ofertadas a princípio pelas operações de paz 
ortodoxas - tais como a narrativa de participação democrática, representatividade, desenvolvimento e direitos fundamentais - para promover outras formas de organização política, social e econômica que não a liberal-ocidental, mais coerentes com as realidades, perspectivas, cosmovisões e reivindicações locais das sociedades pós-conflito.

Não obstante, é necessário apontar que verificam-se também, ainda no escopo crítico da literatura sobre o tema, perspectivas menos otimistas acerca da "paz híbrida”. Aureo de Toledo Gomes (2013, p. 67-68), por exemplo, entende que o processo de hibridização da paz pode vir a servir ao propósito de reforço da paz liberal, cabendo fundamentalmente aos agentes externos a decisão de quais princípios locais incluir em suas formulações de políticas nos cenários pós-conflito. Em perspectiva semelhante, Suthaharan Nadarajah e David Rampton (2015, p. 25-28) indicam que os projetos de paz híbrida tendem a favorecer a penetração dos pressupostos da paz liberal na dimensão cotidiana das populações locais, servindo como plataforma de avanço para a disseminação global de uma ordem neoliberal. Nota-se, portanto, que a identificação e análise de marcos normativos alternativos à paz liberal para a condução das operações de paz contemporâneas é um processo corrente, ainda com poucos resultados concretos obtidos e uma série de questionamentos possíveis para futuras investigações.

\section{Conclusão}

Com base no que foi apresentado ao longo desse artigo, é possível constatar que as operações de paz da ONU (em conjunto com demais organizações internacionais governamentais e não governamentais) não são ferramentas meramente técnicas ou neutras de gestão de conflitos e promoção da paz, mas sim mecanismos que refletem as relações de poder em evidência em contextos particulares da política internacional. Nesse sentido, na primeira seção se trabalhou a questão da diferença nos modelos de atuação das operações de paz no contexto de tensão bipolar própria da Guerra Fria e do período posterior ao conflito. Particular ênfase foi dada à configuração das operações de paz ditas multidimensionais próprias do contexto pós-Guerra Fria, especialmente às operações de peacebuilding e aos processos de construção de governança política, econômica e social implementados por elas. Ainda na primeira seção, foram apresentados os pressupostos centrais do argumento da paz liberal que guia as operações de peacebuilding contemporâneas, 
orientando-as no sentido da promoção da democracia liberal e do livre mercado como estratégias ideais para a reconstrução de cenários pós-conflito.

A segunda seção, por sua vez, foi dedicada à apresentação de algumas das principais críticas direcionadas às operações de paz das Nações Unidas. Por um lado, foram expostas as críticas procedimentais, relacionadas a aspectos pragmáticos, tais como abusos sexuais, impactos econômicos negativos e uso arbitrário da força, eventualmente perpetrados pelos contingentes das operações. Por outro lado, expôs-se também as críticas que aqui chamamos "estruturais", que se utilizam de referenciais teóricos para apontar as relações de poder e dominação inerentes às operações de paz, tanto em sua relação com um contexto de ordem mundial mais amplo - como nos enfoques da Teoria Crítica - quanto de sua incidência nas populações e sociedades locais, como nas perspectivas pósestruturalistas e pós-coloniais.

Levando-se em consideração as discussões delineadas ao longo do texto, esse artigo pretende servir como contribuição referencial para futuras possíveis investigações sobre o tema da construção da paz no cenário internacional. Nesse sentido, destacam-se aqui duas potenciais grandes avenidas de investigação. A primeira delas diz respeito à reflexão acerca da participação dos países do Sul Global nos processos de pacificação e operações de paz. É notório que tais países já participam, em largo número e com amplos contingentes, das operações de paz das Nações Unidas. Contudo, esses países têm a sua participação majoritariamente limitada à contribuição com efetivos militares, ficando excluídos dos processos decisórios e do delineamento da própria ideia de "paz" a ser construída em cenários pós-conflito ${ }^{14}$. Nesse sentido, problematizar novas agendas, doutrinas e abordagens a partir do olhar e vivência do Sul Global pode trazer importantes contribuições ao debate, reflexão e prática da construção da paz no cenário internacional.

Em segundo lugar, ainda numa perspectiva analítica desde o Sul Global, uma importante orientação de pesquisas pode se dar no sentido de identificar e trazer para o debate distintos entendimentos de "paz" e dos processos para a sua construção a partir de cosmovisões, práticas, culturas e saberes dos diversos povos localizados em cenários pós-conflito. Conforme destacado na subseção final do artigo, são vários os desafios nesse sentido. Ainda assim, entende-se que somente a partir desse processo é possível a superação do caráter da construção da paz no cenário internacional enquanto mais um mecanismo, dentre diversos

14 Para mais informações sobre como um ator do Sul Global, no caso o Brasil, participa ativamente na construção da sua própria subalternidade no que toca à construção da paz internacional, ver, por exemplo, Blanco (2017b) . 
outros, de disciplinarização e normalização do Sul Global a partir de parâmetros e modelos arbitrariamente formulados no Norte. Abre-se, assim, espaço para um direcionamento a entendimentos e práticas da construção da paz potencialmente mais emancipatórias e consonantes com as pluralidades e particularidades locais.

\section{Referências}

AMMITZBOELL, Katarina. Unintended consequences of peace operations on the host economy from a people's perspective. In: AOI, C.; DE CONING, C.; NEWMAN, E. (Eds.). Unintended Consequences of Peacekeeping Operations. New York: United Nations University Press, 2007, p. 69-89.

BELLAMY, Alex; WILLIAMS, Paul; GRIFFIN, Stuart. Understanding Peacekeeping. 2. ed. Cambridge: Polity, 2010.

BLANCO, Ramon. Del mantenimiento de la paz al proceso de formación del Estado: un esbozo de los esfuerzos de la ONU para la paz internacional. Foro Internacional, v. LIV, n. 2 (216), p. 266-318, 2014. Disponível em: < http://www.redalyc.org/ pdf/599/59941335002.pdf > . Acesso em: 12 ago. 2017.

BLANCO, Ramon. Normalizando anormais na sociedade internacional: operações de paz, Foucault e a Escola Inglesa. Relações Internacionais, p. 83-107, 2017a. Disponível em: < http://www.scielo.mec.pt/scielo.php?pid = S1645-91992017000100007\&script = sci_ arttext\&tlng $=$ pt $>$. Acesso em 08 mai. 2018.

BLANCO, Ramon. The Brazilian Engagement with Peace Operations: a Critical Analysis. Revista Brasileira de Política Internacional, v. 60, n. 2, p. 1-20, 2017b. Disponível em: < http://www.scielo.br/scielo.php?pid = S0034-73292017000200206\&script = sci_ arttext > . Acesso em 08 mai. 2018.

BLANCO, Ramon. The UN peacebuilding process: an analysis of its shortcomings in Timor Leste. Revista Brasileira de Política Internacional, v. 58, n. 1, p. 42-62, 2015. Disponível em: < http://www.scielo.br/scielo.php?pid = S0034-73292015000100042\&script = sci_ arttext $>$. Acesso em 08 mai. 2018.

BUZAN, Barry; HANSEN, Lene. A evolução dos estudos de segurança internacional. São Paulo: UNESP, 2012.

CAMMACK, Paul. UN Imperialism: Unleashing entrepreneurship in the developing world. Papers in the Politics of Global Competitiveness, 2006.

CELLAMARI, Giovanni. Le operazion di peace-keeping multifunzionali. G. Giappichelli Editore, 1999.

CHANDLER, David. Empire in Denial: The Politics of State-Building. London: Pluto Press, 2006. 
CHOPRA, Jarat. Building state failure in East Timor. Development and Change, v. 33, n. 5, p. 979-1000, 2002.

COX, Robert. Civil Society at the turn of the Millenium: Prospects for an alternative world order. Review of International Studies, v. 25, n. 1, p. 1-38, 1999.

COX, Robert. Gramsci, hegemonia e relações internacionais: um ensaio sobre o método. Gramsci, materialismo histórico e relações internacionais. Rio de Janeiro: UFRJ, 2007, p. 101-123.

COX, R. W. Social Forces, States and World Orders: Beyond International Relations Theory. Millennium: Journal of International Studies, v. 10, n. 2, p. 126-155, 1981.

DE CONING, Cedric; AOI, Chiyuki; THAKUR, Ramesh. Uninteded Consequences of Peacekeeping. 2007. Disponível em: < http://eeas.europa.eu/archives/ifs/ publications2006-2009/articles/book2/book_vol2_part2_chapter23_unintended_ consequences_of_peacekeeping_cedric_de_coning,_chiyuki_aoi_and_ramesh_ thakur.pdf > . Acesso em: 6 ago. 2017.

DPKO - UNITED NATIONS DEPARTAMENT OF PEACEKEEPING OPERATIONS. United Nations Peacekeeping Operations: Principles and Guidelines. 2008. Disponível em: < http://www.un.org/en/peacekeeping/documents/capstone_eng.pdf > . Acesso em: 30 ago. 2017.

DUFFIELD, Mark. Global governance and the new wars: The merging of development and security. New York: Zed Books Ltd., 2001.

FELDBAUM, Harley; LEE, Kelley; PATEL, Preeti. The national security implications of HIV/AIDS. PLoS Medicine, v. 3, n. 6, p. 774-778, 2006.

FUKUYAMA, Francis (1989). The end of history? The national interest, 16: 3-18. Disponível em: < http://www.kropfpolisci.com/exceptionalism.fukuyama.pdf > . Acesso em 20 fev. 2018.

GOMES, Aureo. Da paz liberal à virada local: analisando a literatura crítica sobre peacebuilding. Monções: Revista de Relações Internacionais da UFGD, v. 2, n. 3, p. 46-76, 2013. Disponível em: < http://ojs.ufgd.edu.br/index.php/moncoes/article/ viewFile/2988/1691 > . Acesso em: 3 set. 2017.

GUERRA, Lucas; BLANCO, Ramon. MINUSTAH como Missão Civilizatória: Análise da Política Internacional para a Estabilização do Haiti. Revista de Estudos Internacionais, v. 8, n. 3, p. 259-275, 2017. Disponível em: < http://www.revistadeestudosinternacionais. com/uepb/index.php/rei/article/view/313 > . Acesso em 08 mai. 2018.

HELMAN, Gerald; RATNER, Steven. Saving Failed States. Foreign Policy, v. 89, p. 3-20, 1992. HERZ, Mônica; HOFFMANN, Andrea Ribeiro; TABAK, Jana. Organizações internacionais: história e práticas. 2. ed. Rio de Janeiro: Campus/Elsevier, 2015.

HILL, Jonathan. Beyond the Other? A Postcolonial Critique of the Failed State Thesis. African Identities, v. 3, n. 2, p. 139-154, 2005. 
JAHN, B. One Step Forward, Two Steps Back: Critical Theory as the Latest Edition of Liberal Idealism. Millenium: Journal of International Studies, v. 27, n. 3, p. 613-641, 1998.

KALDOR, Mary. In Defence of New Wars. Stability, v. 2, n. 1, p. 1-16, 2013.

KANT, Immanuel. À paz perpétua. Porto Alegre: L\&PM, 2008.

KENT, Vanessa. Protecting civilians from UN peacekeepers and humanitarian workers: Sexual exploitation and abuse. In: Unintended Consequences of Peacekeeping Operations. New York: United Nations University Press, 2007, p. 44-66.

KOTZÉ, Dirk. Democratisation and development: a difficult relationship. In: Palgrave Advances in Peacebuilding. Hampshire: Palgrave Macmillan, 2010. p. 213-234. (Capítulo 11).

LOCKE, John. Segundo tratado sobre o governo. 2. ed. São Paulo: Abril Cultural, 1978. MAC GINTY, Roger. Gilding the lily? International support for indigenous and traditional peacebuilding. In: RICHMOND, Oliver (Ed.). Palgrave advances in peacebuilding: critical developments and approaches. Hampshire: Palgrave Macmillan, 2010, p. 347-366. (Capítulo 18).

MADISON, James; HAMILTON, Alexander; JAY, John. Os artigos federalistas 1777-1788: edição integral. Rio de Janeiro: Nova Fronteira, 1993.

MONTESQUIEU, Charles de Secondat. O espírito das leis. São Paulo: Saraiva, 1996.

NADARAJAH, Suthaharan; RAMPTON, David. The limits of hybridity and the crisis of liberal peace. Review of International Studies, v. 41, n. 1, p. 49-72, 2015. Disponível em: < http://s3.amazonaws.com/academia.edu.documents/37593234/Nadarajah_ Rampton_Limits_RIS_final_accepted_2014_Article.pdf?AWSAccessKeyId = AKIAIW OWYYGZ2Y53UL3A\&Expires $=1510364453 \&$ Signature $=$ e1 KNv30vltEc5K3TgVczR o2N \% 2FSE \% 3D\&response-content-disposition = inline \% 3B \% 20filename \% 3DThe_ limits_of_hybridity_and_the_crisis_o.pdf > . Acesso em 10 nov. 2017.

NEWMAN, Edward. "Liberal” peacebuilding debates. In: AOI, C.; DE CONING, C.; NEWMAN, E. (Eds.). New perspectives on liberal peacebuilding. New York: United Nations University Press, 2009, p. 26-54. Capítulo 2.

PARIS, Roland. At War's End: building peace after civil conflict. Cambridge University Press, 2004.

PARIS, Roland. International peacebuilding and the "mission civilisatrice". Review of International Studies, v. 28, p. 637-656, 2002. Disponível em: < http://aix1.uottawa. ca/ rparis/RIS_Oct_2002.pdf > . Acesso em: 30 ago. 2017.

PATROLA, José Luis; GOMES, Thalles. Tropas de Desestabilización. Africa, América Latina, cuadernos: Revista de análisis sur-norte para una cooperación solidaria, v. 49, p. 147-153, 2011.

PETTERSSON, Therése; WALLENSTEEN, Peter. Armed Conflicts, 1946-2014. Journal of Peace Research, v. 52, n. 4, p. 536-550, 2015. 
PUGH, Michael. Peacekeeping and Critical Theory. International Peacekeeping, v. 11, n. 1, p. 39-58, 2004.

PUGH, Michael. The political economy of peacebuilding: a critical theory perspective. International Journal of Peace Studies, v. 10, n. 2, p. 23-42, 2005.

RICHMOND, Oliver. A genalogy of peace and conflict theory. In: RICHMOND, Oliver (Ed.). Palgrave advances in peacebuilding: critical developments and approaches. Hampshire: Palgrave Macmillan, 2010, p. 14-38. (Capítulo 1).

RICHMOND, Oliver P. Formação da Paz e Infraestruturas Locais para a Paz. Universitas. Relacoes Internacionais, v. 11, n. 2, p. 73-89, 2013. Disponível em: < https://www. publicacoesacademicas.uniceub.br/relacoesinternacionais/article/download/ 2535/2162 > . Acesso em 10 nov. 2017.

RICHMOND, Oliver. Peace in IR. London: Routledge, 2008.

RICHMOND, Oliver. The transformation of peace. Basingstoke: Palgrave Macmillan, 2005.

RICHMOND, Oliver. UN peace operations and the dilemmas of the peacebuilding consensus. International Peacekeeping, v. 11, n. 1, p. 83-101, 2004.

ROBERTS, David. Beyond the metropolis? Popular peace and post-conflict peacebuilding. Review of International Studies, v. 37, n. 5, p. 2535-2556, 2011.

ROBINSON, William. Promoting polyarchy: 20 years later. International Relations, v. 27, n. 2, p. 228-234, 2013. Disponível em: < https://www.researchgate.net/profile/ William_Robinson17/publication/270711710_Promoting_polyarchy_20_years_later/ links/55f71c5308aec948c466d897/Promoting-polyarchy-20-years-later.pdf > . Acesso em: 31 ago. 2017.

SMITH, Adam. A riqueza das nações: investigação sobre a natureza e suas causas. [s.l.]: Nova Cultura, 1988.

TAYLOR, Ian. Liberal peace, liberal imperialism: a gramscian critique. In: RICHMOND, Oliver (Ed.). Palgrave advances in peacebuilding: critical developments and approaches. Hampshire: Palgrave Macmillan, 2010, p. 154-175. (Capítulo 8).

THEOBALD, Andrew G. Watching the war and keeping the peace: the United Nations Truce Supervision Organization (UNTSO) in the Middle East, 1949-1956. Tese (doutorado), Queen’s University, Kingston, Ontario, Canadá, 2009. Disponível em: < http://qspace. library.queensu.ca/bitstream/handle/1974/1892/Theobald_Andrew_G_200905_PhD. pdf? sequence $=1$ \&is Allowed $=\mathrm{y}>$. Acesso em: 10 nov. 2017 .

UNited NATIONS (UN). An Agenda for Peace. 1992. Disponível em: < http://www. un-documents.net/a47-277.htm > . Acesso em: 27 ago. 2017.

WERNER, Karolina. Rediscovering Indigenous Peacebuilding Techniques: The Way to Lasting Peace? Africa Peace and Conflict Journal, v. 3, n. 2, p. 60-73, 2010.

WILLIAMS, Paul. Security Studies: An Introduction. In: Security Studies: An Introduction. Oxford: Routledge, 2008, p. 1-12. (Capítulo 1). 